Article

\title{
Effect of Nanoparticle Morphology on Pre-Breakdown and Breakdown Properties of Insulating Oil-Based Nanofluids
}

\author{
Yuzhen Lv ${ }^{1,2}$, Yang Ge ${ }^{1, *(1)}$, Zhen Sun ${ }^{2}$, Qian Sun ${ }^{2}$, Meng Huang ${ }^{1}{ }^{(D)}$, Chengrong Li $^{1}$, \\ Bo $\mathrm{Qi}^{1}{ }^{1}{ }^{\mathbb{D}}$, Jinsha Yuan ${ }^{3}$ and Zhaoliang Xing ${ }^{4}$ \\ 1 State Key Laboratory of Alternate Electrical Power System with Renewable Energy Sources, North China \\ Electric Power University, Beijing 102206, China; yuzhenlv@163.com (Y.L.); huang_m2011@163.com (M.H.); \\ lcr@ncepu.edu.cn (C.L.); lqicb@163.com (B.Q.) \\ 2 School of Energy, Power and Mechanical Engineering, North China Electric Power University, \\ Beijing 102206, China; sunzh@ncepu.edu.cn (Z.S.); 15652912576@163.com (Q.S.) \\ 3 School of Electrical Engineering, North China Electric Power University, Baoding 071003, China; \\ yuanjinsha@126.com \\ 4 State Key Laboratory of Transducer Technology, Global Energy Interconnection Research Institute Co. Ltd., \\ Beijing 102209, China; xingzhaoliang007@163.com \\ * Correspondence: geyang-tim@163.com
}

Received: 7 June 2018; Accepted: 25 June 2018; Published: 28 June 2018

\begin{abstract}
Nanoparticles currently in use are challenged in further improving the dielectric strength of insulating oil. There is a great need for a new type of nanoparticle to promote the application of insulating oil-based nanofluids in electric industries. This paper experimentally investigates the effect of nanoparticle morphology on pre-breakdown and breakdown properties of insulating oil-based nanofluids. The positive impulse breakdown voltage of insulating oil can be significantly increased by up to $55.5 \%$ by the presence of $\mathrm{TiO}_{2}$ nanorods, up to 1.23 times that of $\mathrm{TiO}_{2}$ nanospheres. Pre-breakdown streamer propagation characteristics reveal that streamer discharge channels turn into a bush-like shape with much denser and shorter branches in the nanofluid with $\mathrm{TiO}_{2}$ nanorods. Moreover, the propagation velocity of streamers is dramatically decreased to $34.7 \%$ of that in the insulating oil. The greater improvement of nanorods on the breakdown property can be attributed to the lower distortion of the electric field. Thus, when compared with nanospheres, pre-breakdown streamer propagation of nanofluid is much more suppressed with the addition of nanorods, resulting in a greater breakdown voltage.
\end{abstract}

Keywords: nanorod; insulating oil; breakdown strength; streamer propagation; electric field

\section{Introduction}

Nanoparticles have shown a promising prospect in improving the electric performance of dielectric materials [1,2]. The insulating oil-based nanofluids exhibit great potential to address the strong demands for power equipment with large capacity, high dielectric strength and small volume in an ultra-high voltage power grid $[3,4]$. The dielectric strength of insulating oils is closely related to the breakdown event, which is caused by the initiation and propagation of charged gaseous channels called "streamers" at the pre-breakdown stage [5]. Previous experimental evidence for insulating oils has shown that positive streamers emanating from the positive electrode tend to initiate at lower applied voltages and propagate faster and further than negative ones. As a result, impulse pre-breakdown streamers and breakdown under positive polarity constitute a great risk to dielectric strength in power equipment [6,7]. 
Extensive research has been conducted into dispersing nanoparticles into the oil to improve the dielectric strength of the insulating oil [8-11]. The lightning impulse breakdown voltage of insulating oil can be improved by $82.6 \%$ with the addition of $\mathrm{Fe}_{3} \mathrm{O}_{4}$ nanoparticles [8]. However, this conductive nanoparticle may increase the electrical conductivity of the insulating liquid and be influenced by a magnetic field which restricts its practical application [12]. In this case, insulating and semi-conductive nanoparticles (e.g., $\mathrm{Al}_{2} \mathrm{O}_{3}$ and $\mathrm{TiO}_{2}$ ) with lower electrical conductivity are widely used to improve the dielectric strength of the insulating oil. However, the improvement of positive impulse breakdown voltage by these nanoparticles is generally around $30 \%$ under optimum concentrations [13-17]. There is still a bottleneck in further increasing the dielectric strength of nanofluids modified by semiconducting nanoparticles. To date, only spherical nanoparticles have been used to modify the dielectric strength of insulating oil. Therefore, there is a necessity to investigate the effect of the microscopic structure of nanoparticles on the dielectric strength of insulating oil. The nanoparticle morphology may shed light on the enhancement of the dielectric strength of insulating oil-based nanofluid.

In this work, the effect of the $\mathrm{TiO}_{2}$ nanoparticle morphology on the dielectric strength of insulating oil-based nanofluids is investigated. $\mathrm{TiO}_{2}$ nanospheres and nanorods with a similar diameter were prepared by the solvothermal method and used to synthesize insulating oil-based nanofluids. The dielectric strengths of insulating oil and nanofluids with the same nanoparticle concentration were measured. To reveal the breakdown process, the propagation characteristics of pre-breakdown streamers were studied with the help of the schlieren technique. Moreover, the effect mechanism of nanoparticle morphology on the improvement of dielectric strength of insulating oil is proposed.

\section{Experiment}

\subsection{Materials}

$\mathrm{TiO}_{2}$ nanospheres and nanorods modified by oleic acid were synthesized by the solvothermal method in our lab [18]. Naphthenic transformer oil (25\# Karamay) was used as the insulating oil, which was filtered to remove impurities and meet the demand for clean oil defined by CIGRE (International Council on Large Electric Systems) working group 12.17 [19].

\subsection{Preparation of Insulating Oil-Based Nanofluids}

$\mathrm{TiO}_{2}$ nanofluids (NFs) were prepared by dispersing $\mathrm{TiO}_{2}$ nanoparticles into the insulating oil with a concentration of $0.075 \mathrm{vol}$. \% under stirring and ultrasonic treatment. The insulating oil and nanofluids were degassed at less than $1 \mathrm{kPa}$ for $24 \mathrm{~h}$ before testing, and the moisture content of each sample was around $10 \mathrm{ppm}$.

\subsection{Characterization and Measurement}

The morphology of nanoparticle powders was observed by transmission electron microscope (TEM, JEM-2100, JEOL Ltd., Tokyo, Japan). However, limited by the vacuum environment of TEM, the morphology of nanoparticles in nanofluids cannot be observed directly. So, the liquid cell was applied to characterize the morphology of nanoparticles in nanofluids, as shown in Figure 1 [20,21]. The liquid cell was made from two vacuum-tight electron transparent membranes with a controlled separation of about $100 \mathrm{~nm}$ to $1 \mu \mathrm{m}$. Thin SiN films were used as membranes. The cell was filled with the oil. The electron beam was passed through the membranes and oil to allow recording of images [21]. 


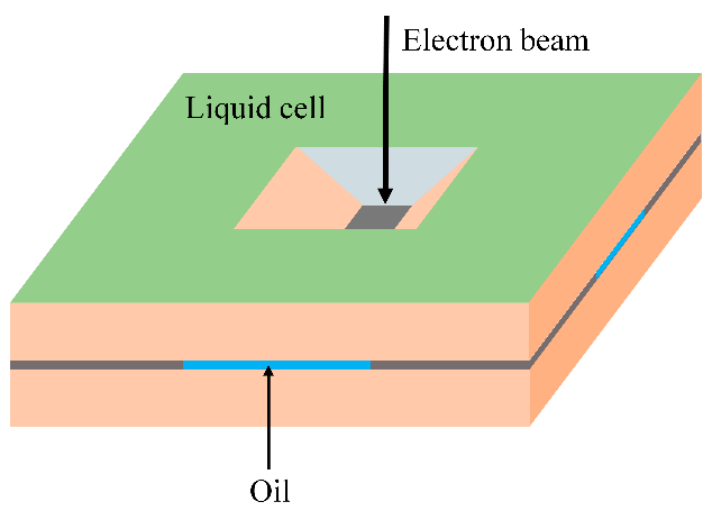

(a)

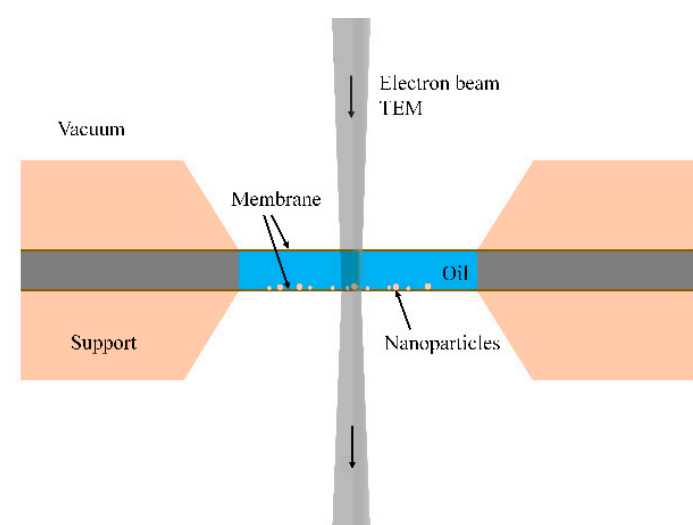

(b)

Figure 1. (a) Schematic of a liquid cell and (b) configuration for electron microscopy in oil.

The breakdown and pre-breakdown properties were investigated by the experimental setup using schlieren technique, as shown in Figure 2 [22]. The breakdown property was measured according to the standard procedures for testing lightning impulse breakdown voltages (IEC60897-1987). A needle-sphere electrode system, with a high voltage tungsten needle (tip radius of $35 \pm 5 \mu \mathrm{m}$ ) opposing a grounded sphere, was located within a test cell made of transparent Perspex sheet, which facilitates the streamer observation. An Intensified Charge Coupled Device (ICCD) camera was used to capture streamer propagation images, which were performed with an electrode gap of $40 \mathrm{~mm}$ under peak voltage of $75 \mathrm{kV}$. The camera works with the help of the laser to meet the need of the schlieren technique. A trigger unit was used to synchronously trigger the impulse generator and camera.

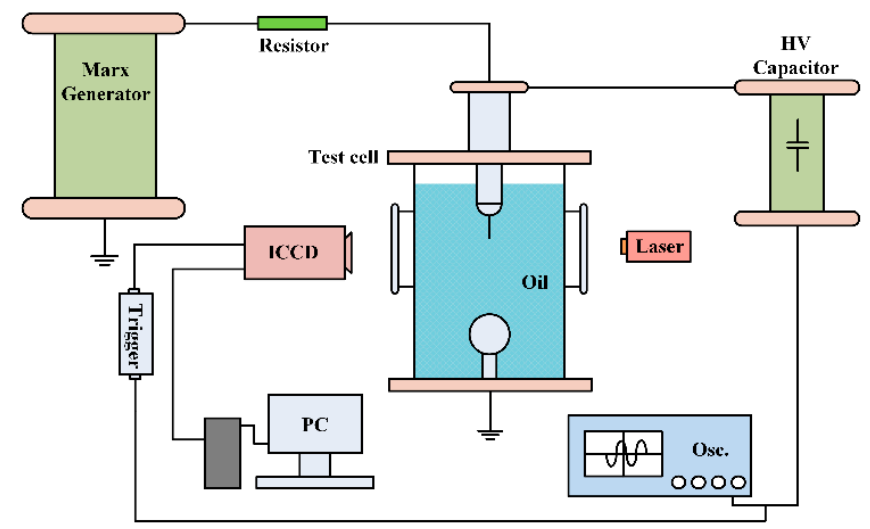

Figure 2. Schematic of experimental setup for breakdown and pre-breakdown measurement.

\section{Results and Discussion}

\subsection{Nanoparticle Morphology}

As shown in Figure 3, the as-prepared nanorods have a small diameter of $4.6 \pm 0.3 \mathrm{~nm}$ and a length of $22.0 \pm 1.1 \mathrm{~nm}$ with a uniform particle size distribution. The nanospheres have a diameter of $4.3 \pm 0.1 \mathrm{~nm}$. After added to oils, nanospheres disperse uniformly, as shown in Figure 4a. Whereas, nanorods tend to contact each other, as shown in Figure $4 \mathrm{~b}$. Moreover, the size of the nanoparticles is observed to be increased. The nanorods have an average diameter of $6.8 \mathrm{~nm}$ and a length of $27.6 \mathrm{~nm}$. And nanospheres with an average diameter of $7.6 \mathrm{~nm}$ are obtained. The reason for the increased particle size is that the exterior of the $\mathrm{TiO}_{2}$ nanoparticles as modified by oleic acid is a hydrophobic alkyl long chain with oil molecules coated on the surface of the $\mathrm{TiO}_{2}$ nanoparticles [23]. 


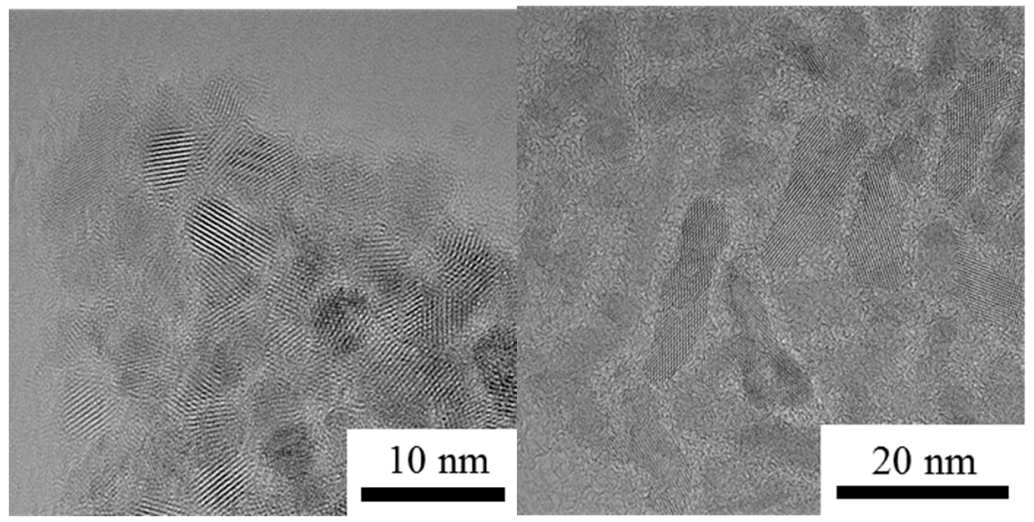

Figure 3. HRTEM (High Resolution Transmission Electron Microscope) images for $\mathrm{TiO}_{2}$ nanospheres and nanorods.
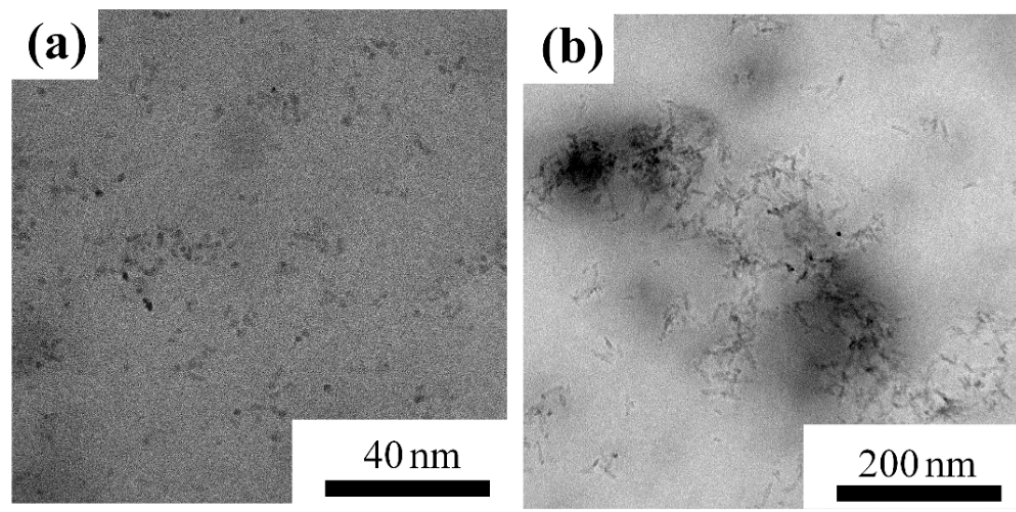

Figure 4. Transmission electron microscope (TEM) images for (a) $\mathrm{TiO}_{2}$ nanospheres and (b) nanorods in nanofluids.

\subsection{Breakdown Property}

The positive breakdown properties of insulating oil and two types of $\mathrm{TiO}_{2}$ nanofluids are shown in Table 1. The breakdown voltages of $\mathrm{TiO}_{2}$ nanofluids are both higher than that of the insulating oil. The nanorods have the best performance in the improvement of the breakdown strength of the insulating oil. In the case of the addition of $\mathrm{TiO}_{2}$ nanorods, the breakdown voltage is increased by up to $55.5 \%$. The improvement is more than twice that of nanospheres, which is only $25.9 \%$. Of particular note, the time to breakdown is significantly increased by $83.2 \%$ with the presence of nanorods. According to the data on time to breakdown, it can be clearly seen that nanorods dramatically change the average propagation velocity of positive streamers, which is of great importance since it has a significant influence on the breakdown voltage of insulating liquid [24,25].

Table 1. Positive breakdown properties of insulating oil and $\mathrm{TiO}_{2}$ nanofluids.

\begin{tabular}{ccccc}
\hline Sample & $\begin{array}{c}\text { Breakdown } \\
\text { Voltage } \mathbf{( k V )}\end{array}$ & $\begin{array}{c}\text { Standard } \\
\text { Deviation } \mathbf{( k V )}\end{array}$ & $\begin{array}{c}\text { Time to } \\
\text { Breakdown }(\boldsymbol{\mu s})\end{array}$ & $\begin{array}{c}\text { Standard } \\
\text { Deviation }(\boldsymbol{\mu s})\end{array}$ \\
\hline Insulating oil & 83.52 & 5.89 & 15.09 & 1.08 \\
Nanofluid (Nanosphere) & 105.19 & 5.76 & 22.38 & 1.98 \\
Nanofluid (Nanorod) & 129.85 & 2.54 & 27.65 & 1.27 \\
\hline
\end{tabular}

\subsection{Pre-breakdown Streamer Propagation}

Figure 5 shows the shapes of pre-breakdown streamers from initiation to their maximum lengths (at $12 \mu \mathrm{s}$ for insulating oil and $15 \mu \mathrm{s}$ for nanofluids) in insulating oil and two types of nanofluids 
with nanospheres and nanorods, respectively. The streamers in insulating oil and nanofluids extend to the ground electrode once derived from the needle electrode. In insulating oil, pre-breakdown streamers show a tree-like shape, the same as those reported in References [26,27]. With the increase of propagation time, only two or three filaments are left to develop into main channels, the distance between which is obviously elongated. When compared with the streamer shapes in the insulating oil, streamers in nanofluids show a bush-like shape and have three considerable differences, especially for nanofluid with nanorods. First, more lateral branches are formed in nanofluid with nanorods than the fluid with nanospheres during the propagation process. Second, branches are much denser, and the distance between main channels is much closer in nanofluid with nanorods than that with nanospheres. Third, it is worth noting that streamer propagation length is kept even shorter in nanofluid with nanorods during the propagation process as presented in Figure 6. In addition, the average propagation velocity of streamers in insulating oil is $2.22 \mathrm{~km} / \mathrm{s}$ according to the slope of curves in Figure 6, which is consistent with propagation velocity of second streamers in mineral insulating oil [6]. Whereas, in nanofluid with nanorods, the velocity is sharply decreased to $0.77 \mathrm{~km} / \mathrm{s}$, even lower than that of $1.04 \mathrm{~km} / \mathrm{s}$ in nanofluid with nanospheres. This observation indicates that the addition of nanoparticles in a rod-like shape has a more significantly inhibiting effect on streamer propagation process than sphere-like ones.

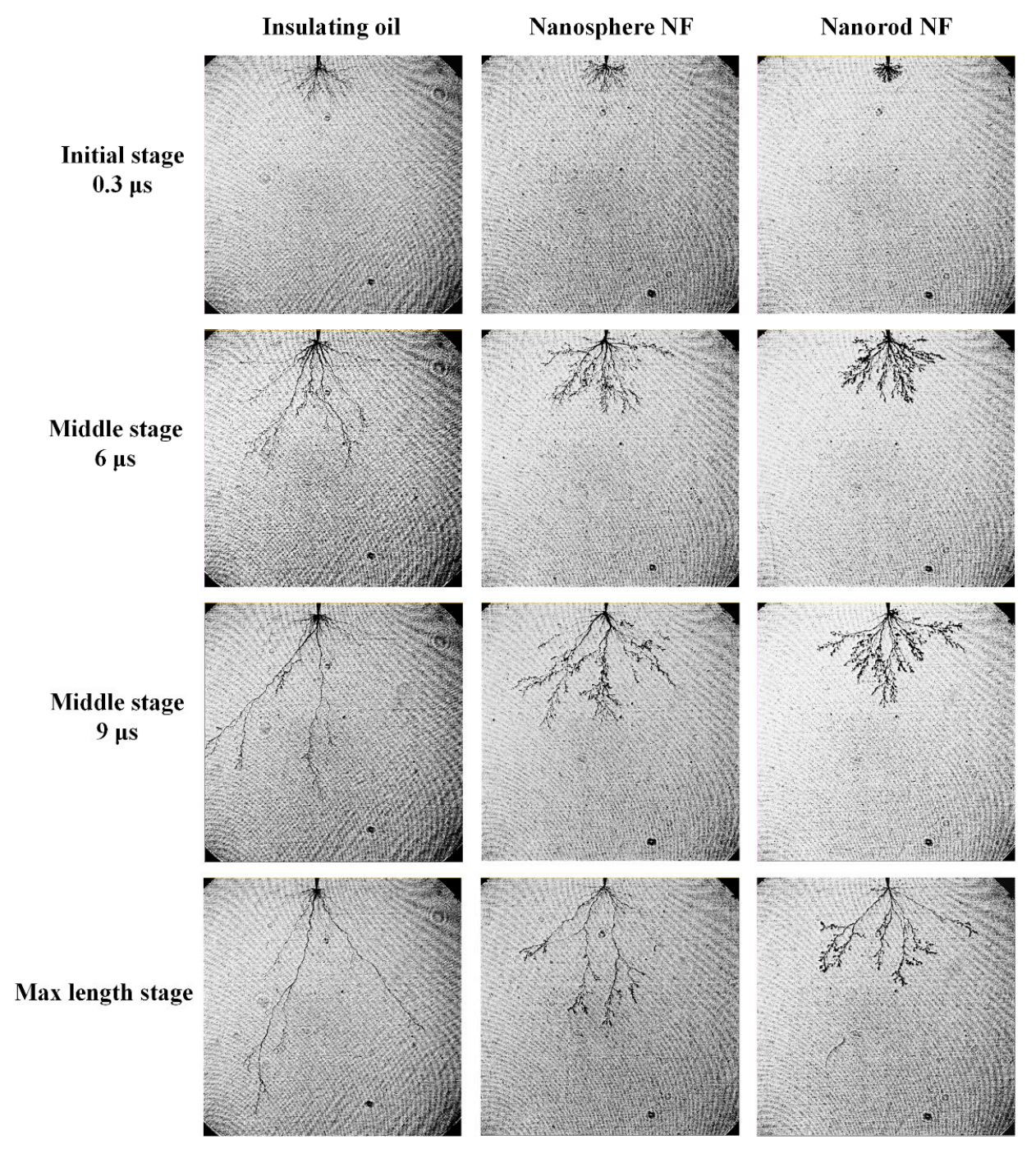

Figure 5. Pre-breakdown streamer propagation images for insulating oil, nanofluid with nanospheres and nanorods. 


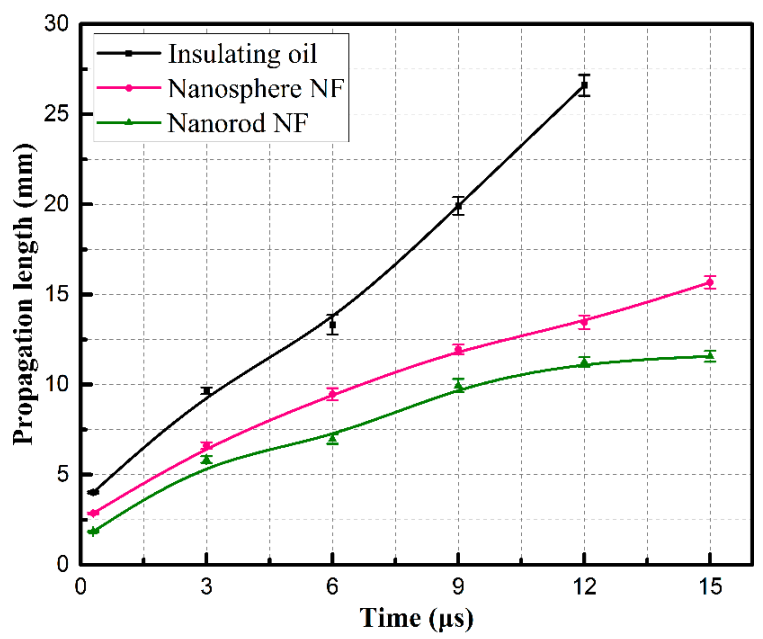

Figure 6. Positive streamer propagation length in insulating oil and nanofluids versus propagation times.

\subsection{Discussion}

In dielectric liquids, the breakdown strength is related to the streamer propagation, which is strongly affected by the electric field $[3,5,6]$. The electrons and positive ions are generated at streamer tips by ionization. When compared with positive ions, electrons move out of the ionization region with a much faster speed, leaving positive ions to become the transient space charges, as presented in Figure 7. In insulating oil, positive ions tend to assemble locally due to the filament shape of streamers, resulting in a greater distortion of the electric field. Thus, the electric field towards the ground electrode is enhanced by the space-charge field created by the positive ions, making it easier for streamers to propagate.

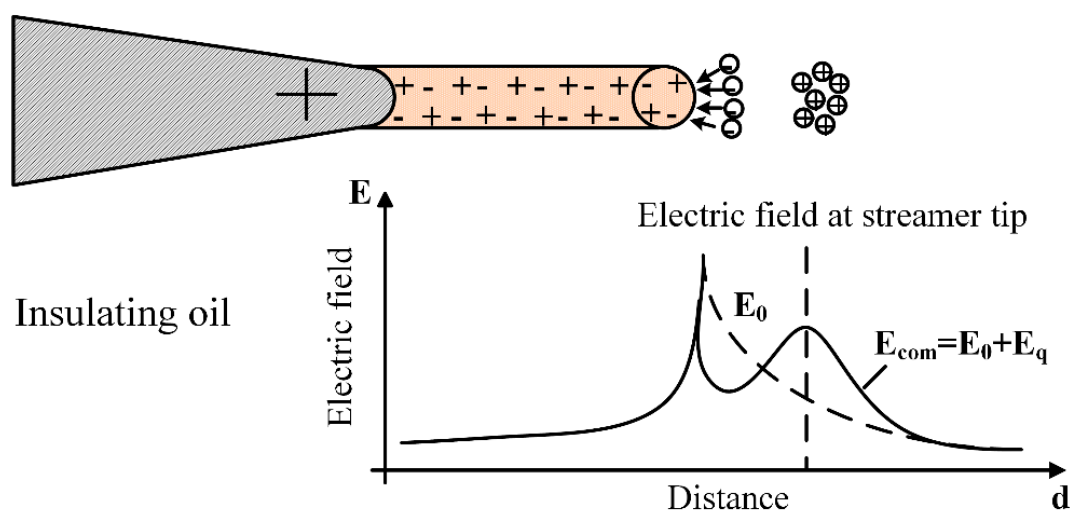

Figure 7. The electric field distribution in insulating oil $\left(\mathrm{E}_{0}\right.$ : applied electric field, $\mathrm{E}_{\mathrm{q}}$ : space-charge electric field).

The greater inhibition on the propagation process of pre-breakdown streamers as well as the improvement on breakdown properties contribute to the difference of nanoparticle morphology. Nanoparticles are considered to have a large area of interface in nanocomposites [28,29], so streamers easily contact nanoparticles $[30,31]$. Whereas, streamers cannot go through the nanoparticles but must go around them, leading to more branches. This is similar to the treeing propagation in polymer nanocomposites proved by the scanning electron micrograph [32,33]. When compared with nanospheres, the streamers are more likely to be blocked by nanorods due to their larger collision cross-section, resulting in more branches. 
Furthermore, the large interfacial layer surrounding nanoparticles is beneficial for charge migration [30,31]. The interaction zone for charge migration is formed when interfacial layers overlap [31,32]. There is a higher probability for nanorods to come in contact with each other (as shown in Figure $4 b$ ), forming an extended interaction zone in which charges can move easily. This has also been reported in nanocomposites modified by $\mathrm{TiO}_{2}$ nanorods [34,35]. The promotion of charge migration in the nanofluid with nanorods is verified by the conductivity test according to the standard of IEC 60247-2004 as presented in Table 2. It should be mentioned that all observed results are mainly related to morphology, and do not consider the change of electron transport properties in the particles. Nanofluid with nanorods has a greater conductivity which means that charges migrate more easily. Some electrons may move in different directions through the interaction zone, further increasing the branches of streamers. In this case, streamer tips of nanofluids with nanorods distribute along an arc, as illustrated in Figure 8. So, the space charges generated at the streamer tips distribute more uniformly compared with that in the insulating oil or nanofluid with nanospheres, as presented in Figure 9. The distortion of the electric field is decreased, which considerably reduces the streamer propagation length. Therefore, the propagation of pre-breakdown streamers in nanofluid is greatly hindered by the presence of nanorods, resulting in the significant improvement in breakdown property.

Table 2. Conductivity of insulating oil and $\mathrm{TiO}_{2}$ nanofluids.

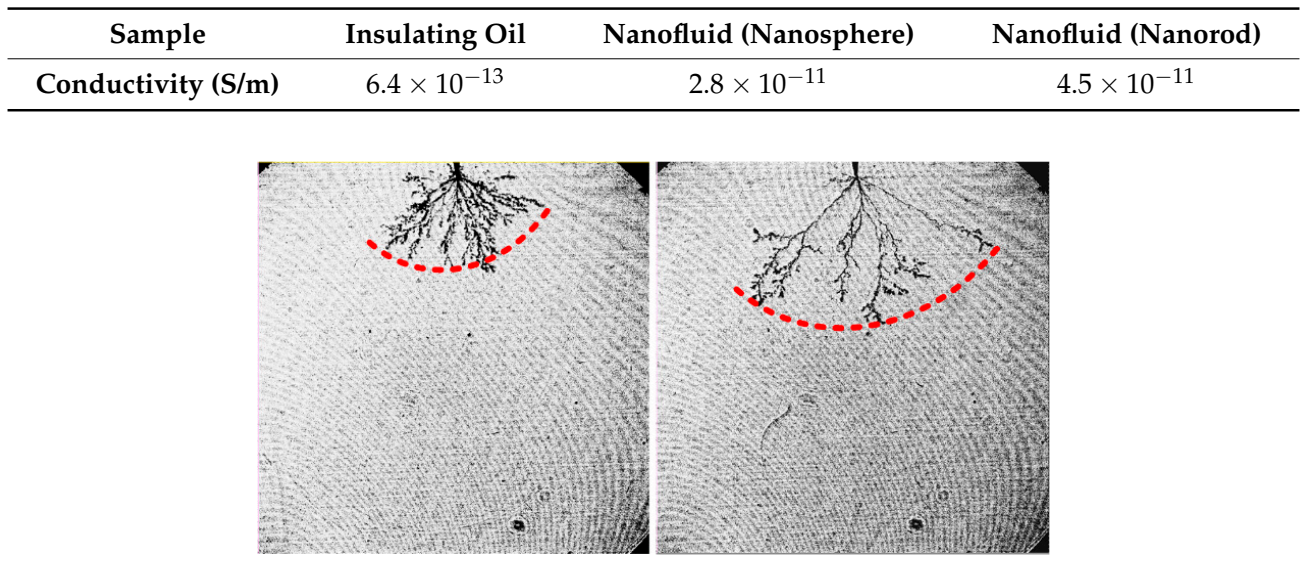

Figure 8. Streamers of nanofluid with nanorods.

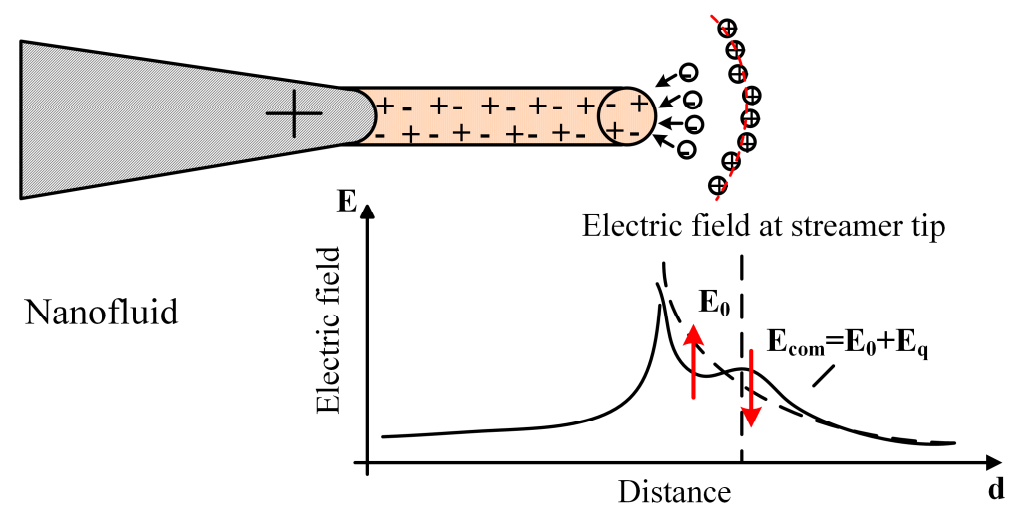

Figure 9. The electric field distribution in the nanofluid ( $\mathrm{E}_{0}$ : applied electric field; $\mathrm{E}_{\mathrm{q}}$ : space-charge electric field).

\section{Conclusions}

This paper investigated the effect of nanoparticle morphology on pre-breakdown and breakdown properties of insulating oil-based nanofluids, revealing the working mechanism for greater improvement 
by nanorods. The improvement of the breakdown property of nanofluid with nanorods is much larger than that of $\mathrm{TiO}_{2}$ nanospheres. Moreover, in nanofluid with $\mathrm{TiO}_{2}$ nanorods, pre-breakdown streamers exhibit a bush-like shape with the most branches and shortest propagation length compared with insulating oil and nanofluid with nanospheres. Thus, the addition of nanorods significantly suppresses the pre-breakdown streamer propagation, leading to a remarkable improvement in the breakdown property. Consequently, it is anticipated that $\mathrm{TiO}_{2}$ nanorods will provide a promising material for improving the dielectric strength of insulating oil and be highly desirable for future application in power equipment.

Author Contributions: Y.L. and Y.G. conceived, designed the experiments and wrote the paper; Z.S. and Q.S. prepared and the materials; Y.G., M.H. and Z.X. performed the experiments and analyzed the data; C.L., B.Q., and J.Y. gave some good advice during the experiments and discussion.

Funding: This research received no external funding.

Acknowledgments: The authors would like to thank the National Natural Science Foundation of China for supporting this research under Contract No. 51337003, 51472084 and State Key Laboratory of Transducer Technology (GEIRI-SKL-2017-009).

Conflicts of Interest: The authors declare no conflict of interest.

\section{References}

1. Guo, N.; Dibenedetto, S.A.; Tewari, P.; Lanagan, M.T.; Ratner, M.A.; Marks, T.J. Nanoparticle, size, shape, and interfacial effects on leakage current density, permittivity, and breakdown strength of metal oxide-polyolefin nanocomposites: Experiment and theory. Chem. Mater. 2010, 22, 1567-1578. [CrossRef]

2. Paszkiewicz, S.; Szymczyk, A.; Pawlikowska, D.; Subocz, J.; Zenker, M.; Masztak, R. Electrically and thermally conductive low density polyethylene-based nanocomposites reinforced by MWCNT or Hybrid MWCNT/Graphene nanoplatelets with improved thermo-oxidative stability. Nanomaterials 2018, 8, 264. [CrossRef] [PubMed]

3. Dung, N.V.; Hoidalen, H.K.; Linhjell, D.; Lundgaard, L.E.; Unge, M. Influence of impurities and additives on negative streamers in paraffinic model oil. IEEE Trans. Dielectr. Electr. Insul. 2012, 20, 876-886. [CrossRef]

4. Lesaint, O.; Jung, M. On the relationship between streamer branching and propagation in liquids: Influence of pyrene in cyclohexane. J. Phys. D: Appl. Phys. 2000, 33, 1360-1368. [CrossRef]

5. Unge, M.; Singha, S.; Dung, N.V.; Linhjell, D.; Ingebrigtsen, S.; Lundgaard, L.E. Enhancements in the lightning impulse breakdown characteristics of natural ester dielectric liquids. Appl. Phys. Lett. 2013, 102, 172905. [CrossRef]

6. Massala, G.; Lesaint, O. A comparison of negative and positive streamers in mineral oil at large gaps. J. Phys. D Appl. Phys. 2001, 34, 1525. [CrossRef]

7. Furusato, T.; Tanoue, H.; Katsuki, S.; Hara, M.; Akiyama, H. Prebreakdown process of a negative nanosecond pulsed discharge in supercritical carbon dioxide. Appl. Phys. Lett. 2014, 7, 343-352. [CrossRef]

8. Segal, V.; Hjortsberg, A.; Rabinovich, A.; Nattrass, D.; Raj, K. AC (60 Hz) and impulse breakdown strength of a colloidal fluid based on transformer oil and magnetite nanoparticles. IEEE Int. Sympos. Electr. Insul. 1998, 2, 619-622.

9. Du, Y.; Lv, Y.; Li, C.; Chen, M.; Zhou, J.; Li, X.; Zhou, Y.; Tu, Y. Effect of electron shallow trap on breakdown performance of transformer oil-based nanofluids. J. Appl. Phys. 2011, 110, 104104. [CrossRef]

10. Sartoratto, P.; Neto, A.; Lima, E.; Rodrigues, S.A.; Morais, P.C. Preparation and electrical properties of oil-based magnetic fluids. J. Appl. Phys. 2005, 97, 10Q917. [CrossRef]

11. Mimura, K.; Kato, K. Enhanced dielectric properties of $\mathrm{BaTiO}_{3}$ nanocube assembled film in metal-insulatormetal capacitor structure. Appl. Phys. Express 2014, 7, 61501. [CrossRef]

12. Yang, Q.; Yu, F.; Sima, W.; Yuan, T.; Jin, Y.; Song, H. Inhibition effect of space charge transportation on impulse breakdown performance of propylene carbonate with $\mathrm{Al}_{2} \mathrm{O}_{3}$ nanoparticles. Appl. Phys. Lett. 2015, 106, 513-612. [CrossRef]

13. Du, Y.; Lv, Y.; Li, C.; Chen, M.; Zhong, Y.; Zhou, J.; Li, X.; Zhou, Y. Effect of semiconductive nanoparticles on insulating performances of transformer oil. IEEE Trans. Dielectr. Electr. Insul. 2012, 19, 770-776. 
14. Sima, W.X.; Cao, X.F.; Yang, Q.; Song, H.; Shi, J. Preparation of three transformer oil-based nanofluids and comparison of their impulse breakdown characteristics. Nanosci. Nanotechnol. Lett. 2014, 6, 250-256. [CrossRef]

15. Liu, R.; Pettersson, L.A.A.; Auletta, T.; Hjortstam, O. Fundamental research on the application of nano dielectrics to transformers. In Proceedings of the 2011 Annual Report Conference on Electrical Insulation and Dielectric Phenomena, Cancun, Mexico, 16-19 October 2011; pp. 423-427.

16. Yao, W.; Huang, Z.; Li, J.; Wu, L.; Xiang, C. Enhanced electrical insulation and heat transfer performance of vegetable oil based nanofluids. J. Nanomater. 2018, 7, 1-12. [CrossRef]

17. Taylor, R.; Coulombe, S.; Otanicar, T.; Phelan, P. Small particles, big impacts: A review of the diverse applications of nanofluids. J. Appl. Phys. 2013, 113, 011301. [CrossRef]

18. Gonzalo-Juan, I.; McBride, R.J.; Dickerson, H.J. Ligand-mediated shape control in the solvothermal synthesis of titanium dioxide nanospheres, nanorods and nanowires. Nanoscale 2011, 3, 3799-3804. [CrossRef] [PubMed]

19. Council on Large Electric Systems (CIGRE). Effect of Particles on Transformer Dielectric Strength; Working Group 17 of Study Committee; Council on Large Electric Systems: Paris, France, 2000.

20. De, J.N.; Ross, F.M. Electron microscopy of specimens in liquid. Nat. Nanotechnol. 2011, 6, 695-704.

21. Ross, F.M. Opportunities and challenges in liquid cell electron microscopy. Science 2015, 350, aaa9886. [CrossRef] [PubMed]

22. Lv, Y.; Ge, Y.; Li, C.; Wang, Q.; Zou, Y.; Qi, B.; Yi, K.; Chen, X.; Yuan, J. Effect of $\mathrm{TiO}_{2}$ nanoparticles on streamer propagation in transformer oil under lightning impulse voltage. IEEE Trans. Dielectr. Electr. Insul. 2016, 23, 2110-2115. [CrossRef]

23. Kim, E.Y.; Choi, H.; Whang, C.M. Controlled growth of $\mathrm{TiO}_{2}$ nanorods capped with carboxylate groups by the solvothermal process. J. Mater. Sci. 2010, 45, 3895-3900. [CrossRef]

24. Jadidian, J.; Zahn, M.; Lavesson, N.; Widlund, O.; Borg, K. Impulse breakdown delay in liquid dielectrics. Appl. Phys. Lett. 2012, 100, 192910. [CrossRef]

25. Dung, N.V.; Høidalen, H.K.; Linhjell, D.; Lundgaard, L.E.; Unge, M. Effects of reduced pressure and additives on streamers in white oil in long point-plane gap. J. Phys. D Appl. Phys. 2013, 46, 255501-255516. [CrossRef]

26. Beroual, A.; Zahn, M.; Badent, A.; Kist, K.; Schwabe, A.J.; Yamashita, H.; Yamazawa, K.; Danikas, M.; Chadband, W.G.; Torshin, Y. Propagation and structure of streamers in liquid dielectrics. IEEE Trans. Electr. Insul. Mag. 1998, 14, 6-17. [CrossRef]

27. Dung, N.V.; Hoidalen, H.K.; Linhjell, D.; Lundgaard, L.E.; Unge, M. Influence of impurities and additives on positive streamers in paraffinic model oil. IEEE Trans. Dielectr. Electr. Insul. 2012, 19, 1593-1603. [CrossRef]

28. Wang, Z.; Liu, J.; Cheng, Y.; Chen, S.; Yang, M.; Huang, J.; Wang, H.; Wu, G.; Wu, H. Alignment of boron nitride nanofibers in epoxy composite films for thermal conductivity and dielectric breakdown strength improvement. Nanomaterials 2018, 8, 242. [CrossRef] [PubMed]

29. Wang, Y.; Wang, C.; Zhang, Z.; Xiao, K. Effect of nanoparticles on the morphology, thermal, and electrical properties of low-density polyethylene after thermal aging. Nanomaterials 2017, 7, 320. [CrossRef] [PubMed]

30. Lewis, T.J. Interfaces: Nanometric dielectrics. J. Phys. D: Appl. Phys. 2005, 38, 202-212. [CrossRef]

31. Tanaka, T. Dielectric nanocomposites with insulating properties. IEEE Trans. Dielectr. Electr. Insul. 2005, 12, 914-928. [CrossRef]

32. Nelson, J.K. Dielectric Polymer Nanocomposites, 7th ed.; Springer: New York, NY, USA, 2010; pp. 198-226.

33. Tanaka, T.; Matsunawa, A.; Ohki, Y.; Kozako, M.; Kohtoh, M.; Okabe, S. Treeing Phenomena in Epoxy/ Alumina Nanocomposite and Interpretation by a Multi-core Model. IEEJ Trans. Fund. Mater. 2007, 126, 1128-1135. [CrossRef]

34. Zerjav, G.; Arshad, M.S.; Djinovic, P.; Junkar, I.; Kovac, J.; Zavasnik, J.; Pintar, A. Improved electron-hole separation and migration in anatase $\mathrm{TiO}_{2}$ nanorod/reduced graphene oxide composites and their influence on photocatalytic performance. Nanoscale 2017, 9, 4578-4592. [CrossRef] [PubMed]

35. Nam, S.H.; Ju, D.W.; Boo, J.H. Comparison of photovoltaic properties of $\mathrm{TiO}_{2}$ electrodes prepared with nanoparticles and nanorods. J. Nanosci. Nanotechnol. 2014, 14, 9406-9410. [CrossRef] [PubMed]

(C) 2018 by the authors. Licensee MDPI, Basel, Switzerland. This article is an open access article distributed under the terms and conditions of the Creative Commons Attribution (CC BY) license (http:/ / creativecommons.org/licenses/by/4.0/). 